\title{
Spontaneous Sigmoid Colon Perforation Based on Endometriosis in Term Pregnancy - Case Report
}

\author{
Daniel Driak ${ }^{1 *}$, Petra Bolehovska ${ }^{1}$ and Zuzana Spurkova ${ }^{2}$
}

${ }^{1}$ Clinic of Gynaecology and Obstetrics, The First Medical Faculty of Charles University and Hospital Bulovka, Prague, czech republic

${ }^{2}$ Department of Pathology, The First Medical Faculty of Charles University and Hospital Bulovka, Prague, czech republic

${ }^{*}$ Corresponding author: Dr. Daniel Driák, Ph.D., Clinic of Gynaecology and Obstetrics, The First Medical Faculty of Charles University and Hospital Bulovka, Prague, Gynekologicko-porodnická klinika 1. LF UK, Nemocnice Na Bulovce, Budínova 2, 18081 Praha 8, czech republic, Tel: 266083232; Fax: 283840507; E-mail: driak@seznam.cz

Received date: February 20, 2018; Accepted date: March 28, 2018; Published date: March 31, 2018

Copyright: (C) 2018 Driak D, et al. This is an open-access article distributed under the terms of the Creative Commons Attribution License, which permits unrestricted use, distribution, and reproduction in any medium, provided the original author and source are credited.

Citation: Driak D, Bolehovska P, Spurkova Z (2018) Spontaneous Sigmoid Colon Perforation Based on Endometriosis in Term Pregnancy - Case Report. Crit Care Obst Gyne. Vol.4 No.1:3.

\section{Abstract}

The case report describes a woman with acute, spontaneous sigmoid colon perforation based on deep endometriosis in advanced stage of pregnancy. The 33-yearold white woman was admitted to our clinic at $37+6$ weeks of pregnancy with symptoms of increasing abdominal pain successively changing the site of maximum. Due to suspicion of acute appendicitis, acute caesarean section, sigmoid resection and end-to-end anastomosis, appendectomy was performed. Spontaneous perforation associated with intestinal endometriosis in pregnancy is scarcely reported, some seven cases have been published in the English literature. To the best of our knowledge, this is the second case report of sigmoid colon perforation due to endometriosis during pregnancy.

\section{Key words:}

Endometriosis; Sigmoid colon perforation; Term pregnancy

\section{Introduction}

Despite more than 100 years of research, endometriosis remains a rather strange and in some cases unpredictable disease. Its morphologic background is in endometrium-like tissue localized somewhere outside of endometrial cavity. With the exception of heart and spleen, endometriosis occurs at all organs and tissues of human body. Endometrioid lesions were histologically detected both at usual gynaecological localizations, e.g. ovaries, peritoneum, cervix, vagina, sacrouterine liggaments, scars after episiotomies and caesarean sections, and at extragenital sometimes curious sites, e.g. bladder, appendix, bowels, umbilicus, mammila, nasal mucosa, lungs, brain etc. Lots of theories have proved multifactorial ethiology with genetic, anatomical, hormonal, immunological, angiogenetic and other, at the time unknown factors [1-4].
Endometriosis affects approximately $10-15 \%$ of reproductiveaged women [5], however in subgroup of women suffering from sterility up to $50 \%$ and in subgroup of women suffering from pelvic pain up to $80 \%$. Endometriosis does not develop before menarche and is very rare in women after menopause without hormonal (estrogene) replacement therapy $[1,3,6]$. Hormonal dependent lesions follow the regular cyclical fluctuating of 17beta-oestradiol and progesterone. Almost $1 / 3$ of affected women had no symptoms, intensity and character of symptoms does not depend on the extent but localization, and substantial part of cases clears up spontaneously. About $1 / 2$ half of patients cannot become pregnant, however, if pregnancy succeeds the state of patient may be improved. Despite activated macrophages in peritoneal fluid and altered endometrium, fertilization and nidation occur. During pregnancy due to physiological amenorrhea and hormonal changes, deposits of ectopic endometrium inactivate, regress, are resorbed and healed.

Most of lesions are typical, colored with hemosiderin and hemofuscin as degradation product of menstruating blood, however untypical lesions (stromal, whitish, yellowish, early reddish, subovarial adhesions, peritoneal defects - AllenMasters syndrome) are not rare and make difficulties with visualization and detection. The therapy should be individualized and complex, i.e. surgical removal of lesions combined with long-term (6-48 months) hormonal blocking of menstruation. Due to atypical lesions and hormonal receptors variability, both surgical and hormonal therapy remains burdened with a high rate of recurrencies [1,3,7-9]. Even though it is believed to be a progressive disease, progression was not seen in some women followed for more than 1 year without surgery [10].

\section{Case Report}

In February 2015, 8.15 a.m., a 33-year-old woman of caucasian race, $1 / 0$, was admitted in emergency duty to our clinic at $37+6$ weeks of pregnancy with "contractions". The woman did not suffer from any other complaints (diarrhoea, nausea, vomiting, fever, dysuria), tendency to constipation occured over 
a long period. The general physical examination was normal, cardio-pulmonally stabilized (blood pressure 144/71 torr, heart rate $94 \mathrm{bpm}$ ), mediosacral cervix $1.5 \mathrm{~cm}$ for one finger to the head, position longitudinal, membranes were not ruptured, no signs of bleeding. Group B Streptococci were negative. Ultrasound showed biometry of foetus matching to 38 weeks, normohydramnion, normal Doppler's flowmetry, placenta localized on the front wall without signs of abruption. Cardiotocografy was physiological.

The previous development of pregnancy was normal without hospitalization. The patient was on anti-anaemics (ferrous sulfate 1 tbl. p.o. a day), in outpatient's department of gynaecology examined for suspicion of endometriosis without any other dealing, in anamnesis no diseases, operation or other medications were reported. Actual laboratory tests with the exception of white blood cells $20.2 \times 109 / \mathrm{L}, \mathrm{CRP} 10.6 \mathrm{mg} / \mathrm{L}$, AST $0.57 \mu \mathrm{kat} / \mathrm{L}$, ALT $0.59 \mu \mathrm{kat} / \mathrm{L}, \mathrm{ALP} 3.67 \mu \mathrm{kat} / \mathrm{L}$, were in physiological range.

The patient expected the start of labour, however, the character of pains was not typical. The pain started early in the morning (5.00 a.m.) in left hypogastrium and during several hours spread to the whole abdomen, the patient localized the maximum of pains to uterus. There were no signs of peritoneal irritation. Despite of increasing intensity of pain, there were no development on cervix and finding remained almost the same. In the afternoon pain moved to the right mesogastrium, later both mesogastriums and uterus were painful, contractions could not be distinguished from signs of peritoneal irritation. Gynaecologist in duty recommended ultrasound on appendix and surgical consultation to exclude acute diverticulitis and appendicitis.

Radiologist's ultrasound indicated hydronephrosis grade III on the right side, some free fluid at bases of caecum, appendix not seen, colon descendent filled with content.

The same day together with surgeons with regard to increasing signs of peritoneal irritation and no development on cervix, we decided to perform acute caesarean section with abdominal revision focused on caecum and appendix under the antibiotics amoxycilinum/acidum clavulanicum $1.2 \mathrm{~g}$ and metronidazolum $0.5 \mathrm{~g}$ i.v.

The incision according to Pfannenstiel was performed, at the moment of peritoneal opening, the purulent secretion above and next to uterus was observed, the samples for aerobic and anaerobic microbial culture were taken. Baby-girl was measured: 3000 G/49 cm, Apgars's score 5-8-9, pH 7.284 and 7.307. After having sutured hysterotomy, together with surgeon peritoneal cavity and bowels were controlled. Lot of purulent secretion and slightly irritated appendix in subcaecal position were observed, however, maximum of changes found at left mesohypogastrium. There were detected fibrin coatings and signs of inflammation on the left side of uterus, localized peritonitis bordered by left edge of uterus and left adnexa, perforation on anti-mesenterial side of sigmoid intestine and surrounding wall of colon inflamed, infiltrated and fragile. In distance of $10 \mathrm{~cm}$ the sigmoid colon was covered with some not-inflamed diverticles. The diagnosis was established as the perforation of inflamed sigmoid diverticle.

About $20 \mathrm{~cm}$ part of sigmoid colon was resected with end-toend anastomosis. In addition, the appendectomy was performed as well. Peroperatively, antibiotics were switched to piperacilinum/tazobactam $4.5 \mathrm{~g}$ iv. After flushing of peritoneal cavity with iodine solution, stopping the diffusive bleeding from fragile, inflamed tissue, and drainage the abdominal wall was sutured lege artis, blood loss $500 \mathrm{~mL}$, total time of operation included total anaesthesia $2 \mathrm{~h} 30 \mathrm{~min}$.

After the operation, the patient was intensively observed at gynaecological emergency unit. Five days of parenteral nutrition (Oliclinomel $2000 \mathrm{~mL}$ i.v./24 hours and crystaloids), miniheparinization (enoxaparinum $0.4 \mathrm{~mL} s c . / 24 \mathrm{~h}$ ), common analgetics, prokinetics (metoclopramidi hydrochloridum $10 \mathrm{mg}$ iv. each $8 \mathrm{~h}$ ), antiulcerosa (omeprazolum $40 \mathrm{mg}$ iv. a $12 \mathrm{~h}$ ) were administered, antibiotics were continued: 3 days of piperacilinum/tazobactam $4.5 \mathrm{~g}$ iv. each 8 hours, then switched to 7 days of ertapenemum $1 \mathrm{~g}$ iv. each 24 hours plus ofloxacinum $400 \mathrm{mg}$ iv. each 12 hours. Since the 4th day after caesarean section the patient was treated with metoprolol tartrate 50-0-50 $\mathrm{mg}$ p.o. on for hypertension. Nasogastric sonde and rectal tube were on site up to 6th day after the operation when the peristaltics renewed completely.

In laboratory, blood count did not significantly changed - $\mathrm{Hb}$ $116.0 \mathrm{~g} / \mathrm{L}$, PLT $238.0 \times 10^{9} / \mathrm{L}$, procalcitonin 0,42 $\mathrm{\mu g} / \mathrm{L}$, fibrinogen $7.71 \mathrm{~g} / \mathrm{L}$, liver enzymes were transiently elevated, WBC transiently increased to $26 \times 10^{9} / \mathrm{L}, \mathrm{CRP}$ to $294.1 \mathrm{mg} / \mathrm{L}$. The pathological level of Escherichia coli was detected in the microbial culture in purulent sample from abdominal cavity. The same pathogen was found in hemoculture and from the placenta's scratch.

Histopathological results confirmed perforation of sigma that was partially blocked with polypoid deposit of decidualized endometriosis extending into the lumen of intestine, other decidualized endometriosis was found in appendix (Figure 1). The patient healed per primam intentionem was discharged at good condition on the 15th day after surgery. 

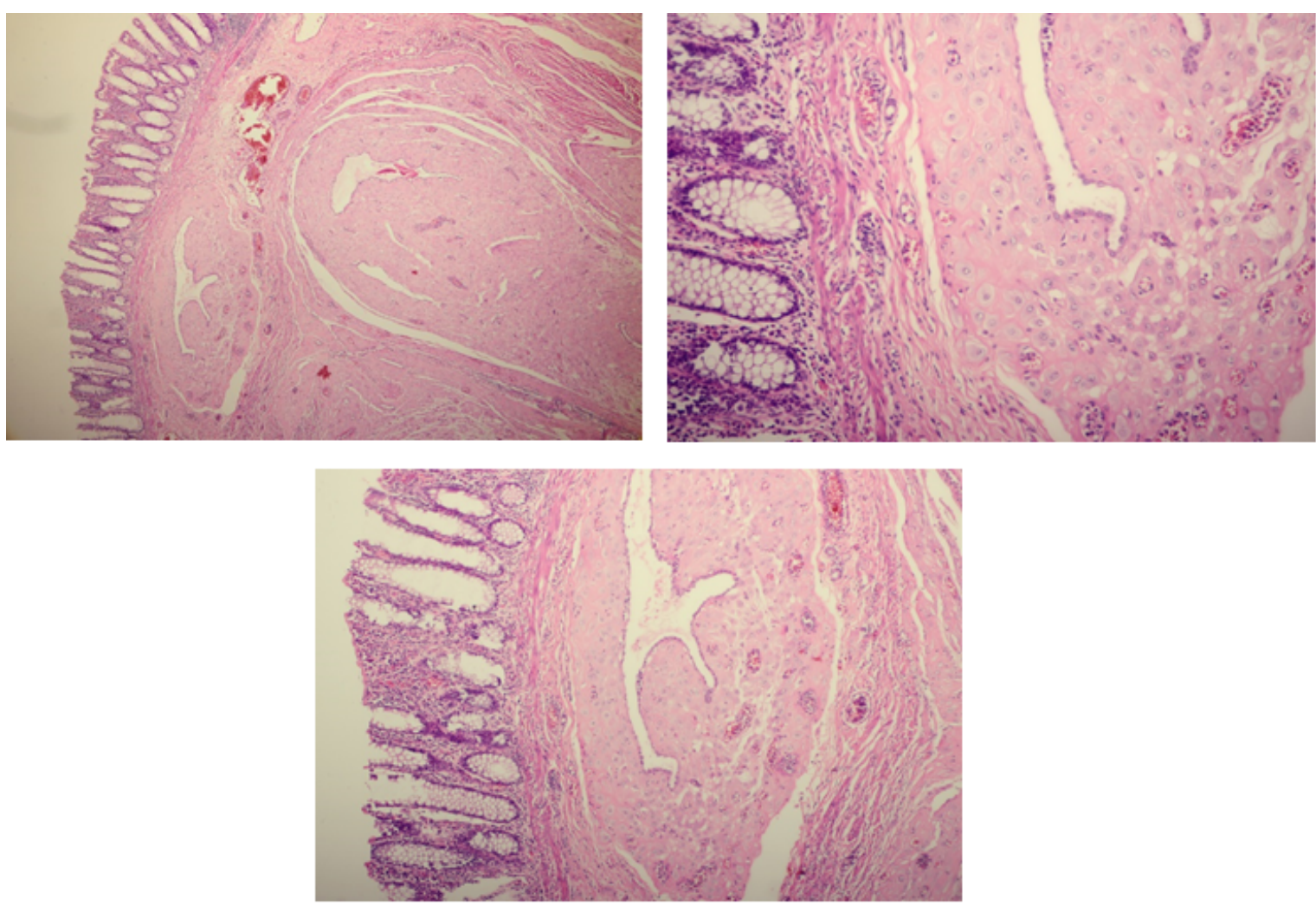

Figure 1 Histological results of sigma.

\section{Discussion}

As a rather enigmatic disease, pathophysiology, progression, and natural history of endometriosis remains poorly understood. Intestinal involvement is the most common of extragenital forms, and occurs in 3-7\% [11], resp. 5-15\% [3] of all patients with endometriosis. Distribution in bowels ranges (Table 1).

Table 1 Distribution of intestinal endometriosis [3].

\begin{tabular}{|l|l|}
\hline Localization & Incidence [\%] \\
\hline rectum & $72-85$ \\
\hline sigmoideum & $10-20$ \\
\hline caecum and appendix & 10 \\
\hline terminal ileum & 5 \\
\hline
\end{tabular}

Specific symptoms are absent in $30-95 \%$ of patients, intestinal endometriosis typically takes the form of asymptomatic serosal implants. The most common symptom, recurrent but acyclic abdominal pain reaches up to $70 \%$ of cases, the complete intestinal obstruction occurs in less than $1 \%[3,12]$. Other symptoms like constipation, dyschesia, enterorrhage, hematochezia, painfull peristaltics, diarrhoea, painfull sitting, subileus, ascites, occur in $10-50 \%$ [3].

Spontaneous intestinal perforation due to endometriosis is a very rare complication, totally some twenty cases [13] and some seven cases in pregnancy have been reported in the
English literature [14]. Endometrioma surrounded with tuboovarian abscess secondarily eroding the sigmoid colonic wall in a 38-year-old, non-pregnant women was revealed by CT scanning, confirmed by surgery and published in 1988 [15].

In 1977, Clement as the first described perforation of the sigmoid colon in a 28-year-old woman during the 37th week of pregnancy [16]. Perforation of appendix in a 23-year-old Nigerian Igbo woman during the 35th week of pregnancy was reported by Gini et al. [17] and in a 25-year-old woman at the 26th week of gestation by Nakatani et al. [18]. In both cases, histological results showed appendiceal wall replaced extensively by decidualized endometriotic tissue.

In 2010, firstly Pisanu et al. published rectal perforation due to endometriosis in a 37-year-old woman hospitalized at the 30th week of gestation. The symptoms were suggestive of pyelonephritis, after 3 weeks the premature delivery through a caesarean section was performed. On the 2 nd postoperative day abdominal CT showed pelvic abscess and free air in the peritoneal cavity, afterwards Hartmann operation was performed [13].

In 2013, firstly Nishikawa et al. published endometriosisinduced ileal perforation with massive hemorrhage that required caesarean section, right hemicolectomy and terminal ileum resection at the 33rd week of gestation [14].

The diagnosis of an intestinal perforation during pregnancy especially in the third trimester might be extraordinarily difficult. Symptoms are similar to appendicitis, diverticulitis, enterocolitis 
(morbus Crohn), ischemic colitis, colon irritable syndrome, colorectal cancer, even though to pyelonephritis which can delay diagnosis and have fatal consequences. Hotly discussed may be our access to perform resection of sigmoid colon with end-toend anastomosis. Lot of surgeons prefer temporary outlet (colonostomia) with returning after interval 4-6 months. Reasons for immediate anastomosis were minimal contamination of peritoneal cavity, peritonitis localized to relatively small region, anatomical condition, stable patient and total time of operation.

We suppose during pregnancy, the endometriosis became inactivated, chronic, and probably exacerbated in the final stage of pregnancy due to constipation and partial obstruction of large intestine. The endometriosis-induced intestinal perforation in pregnancy remains rare complication, however can cause lifethreatening situation for both the mother and baby especially in case of delayed intervention and considerably preterm delivery. Above that, with regard to an increasing age of the first delivery, a growing number of women with severe endometriosis conceive through assisted reproductive technology. Multidisciplinary cooperation is necessary during patient care.

\section{Conclusion}

We reported the case of spontaneous sigmoid colon perforation based on endometriosis in in the 33-year-old woman at 38th week of pregnancy. According to PubMed, our work is the second case report of sigmoid colon perforation due to endometriosis during pregnancy.

\section{References}

1. Giudice LC [2010] Clinical practice. Endometriosis. N Engl J Med 362: 2389-98.

2. Jirátko A (2002) Léčba katameniálního pneumothoraxu zavedením mireny - kazuistika. Gynekolog 11: 221.

3. Kučera E (2008) Endometrióza. Praha, Maxdorf pp: 172.

4. Montalto M, Santoro L, D'Onofrio F, Gallo A, Campo, S, et al. (2010) Endometriosis, need for a multidisciplinary clinical setting: the internists point of view. Intern Emerg Med 5: 463-467.

5. Eskenazi B, Warner ML (1997) Epidemiology of endometriosis. Obstet Gynecol Clin North Am 24: 235-258.
6. Christodoulakos G, Augoulea A, Lambrinoudaki I, Swioulas V, Creatsas G (2007) Pathogenesis of endometriosis: the role of defective 'immunosurveillance'. Eur J Contracept Reprod Health Care 12: 194-202.

7. Kudela M, Pilka R, Hejtmánek P, Ondrová D (2010) Results of laparoscopic treatment of deep and rectovaginal septum endometriosis. Gynekolog 19: 171- 174.

8. Vercellini P, Fedele L, Pietropaolo G, Frontino G, Somigliana E, et al. (2003) Progestogens for endometriosis: forward to the past. Hum Reprod Update 9: 387-396.

9. Yeung PP, Shwayder J, Pasic RP (2009) Laparoscopic management of endometriosis: comprehensive review of best evidence. J Minim Invasive Gynecol 16: 269-281.

10. Koninckx P, Ussia A, Adamyan L, Wattiez A, Donnez J (2012) Deep endometriosis: definition, diagnosis, and treatment. Fertil Steril 98: 564-571.

11. Witz CA (1999) Current concepts in the pathogenesis of endometriosis. Clin Obstet Gynecol 42: 566-585.

12. Garg NK, Bagul NB, Doughan S, Rowe PH (2009) Intestina endometriosis - a rare cause of colonic perforation. World J Gastroenterol 15: 612-614.

13. Pisanu A, Deplano D, Angioni S, Ambu R, Uccheddu A (2010) Rectal perforation from endometriosis in pregnancy: case report and literature review. World J Gastroenterol 16: 648-651.

14. Nishikawa A, Kondoh E, Hamanishi J, Yamaguchi K, Ueda A, et al. (2013) Ileal perforation and massive intestinal haemorrhage from endometriosis in pregnancy: case report and literature review. Eur J Obstet Gynecol Reprod Biol 170: 20-24.

15. Ledley, GS, Shenk, IM, Heit, HA (1988) Sigmoid colon perforation due to endometriosis not associated with pregnancy. Am J Gastroenterol 83: 1424-1426.

16. Clement PB (1977) Perforation of the sigmoid colon during pregnancy: a rare complicatuion of endometriosis. Case report. $\mathrm{Br}$ J Obstet Gynaecol 84: 548-550.

17. Gini PC, Chukudebelu WO, Onuigbo WI (1981)Perforation of the appendix during pregnancy: a rare complication of endometriosis. Br J Obstet Gynaecol 88: 456-458.

18. Nakatani Y, Hara M, Misugi K, Korehisa H (1987) Appendiceal endometriosis in pregnancy. Report of a case with perforation and review of the literature. Acta Pathol Jpn 37: 1685-1690. 